\title{
The Commodity Price and Exchange Rate Dynamics
}

\author{
Liping Zou ${ }^{1^{*}}$, Boliang Zheng², Xiaoming Li ${ }^{1}$ \\ ${ }^{1}$ School of Economics and Finance, Massey University, Auckland, New Zealand \\ ${ }^{2}$ School of Accountancy, Jiangxi University of Finance and Economics, Nanchang, China \\ Email: ^L.Zou@massey.ac.nz
}

How to cite this paper: Zou, L.P., Zheng, B.L. and Li, X.M. (2017) The Commodity Price and Exchange Rate Dynamics. Theoretical Economics Letters, 7, 1770-1793. https://doi.org/10.4236/tel.2017.76120

Received: August 23, 2017

Accepted: October 17, 2017

Published: October 20, 2017

Copyright (c) 2017 by authors and Scientific Research Publishing Inc. This work is licensed under the Creative Commons Attribution International License (CC BY 4.0).

http://creativecommons.org/licenses/by/4.0/

\section{c) (i) Open Access}

\begin{abstract}
This paper investigates the dynamic relationship between the commodity price and the exchange rate in Australia and New Zealand. We focus on Australia and New Zealand. Not only do their primary commodities account for significant shares of their exports, but also their currencies share some distinctive characteristics that are unique from other commodity currencies. Using country-specific commodity price indices, we examine the relationship between the departure of currency value from its fair value and fundamental macroeconomic variables. Evidence of a strong and robust relationship between the exchange rate and the commodity price has been found. Results indicate that the commodity price can be used to improve the forecast ability of the future exchange rate. Our commodity-price-augmented exchange rate forecasting model consistently outperforms the random-walk model, for both in-sample and out-of-sample forecasting. These results shed some extra lights on policymaking for countries that rely on primary commodity production, and attempt to move towards floating exchange rate regimes as part of their global market liberalization process.
\end{abstract}

\section{Keywords}

Exchange Rate, Commodity Price, Forecasting

\section{Introduction}

In past few decades, many attempts to investigate the relation between fundamental macroeconomic variables and exchange rates have been proven to be failure, not to mention numerous unsuccessful endeavours that economists have made on building various types of exchange rate forecasting models. In early 1970s, after the post-war Bretton Woods system of fixed exchange rates col- 
lapsed, a large number of industrialized economies shifted to floating exchange rate regimes. Thus, lots of interests have been put on foreign exchange markets studies. Majority of these work focused on the development of macroeconomic variables based empirical models when forecasting future exchange rates. Meese and Rogoff [1] [2] concluded that there are no exchange rate forecasting models that could outperform a simple naïve model, i.e. a random walk model, for short to medium time horizons. Subsequent attempts have been undertaken to develop a suitable model to forecast exchange rate, but many failed to do so. Therefore, a simple random walk model has become a benchmark when evaluating exchange rate forecasting performance.

Recent literatures on exchange rate determination and forecasting are in line with the propositions found decades ago. Many empirical results conclude that the exchange rate follows a random walk process, and changes in exchange rate are unpredictable, and currencies for high-inflation countries tend to depreciate in long term with the magnitude being approximately the inflation differential. Movements of the actual exchange rate appear to be sometimes overshot and then followed by a smooth adjustment to the equilibrium [3] [4] [5] [6].

There has been a strand of research investigating countries with differing exchange rate regimes and economic structures. In particular, countries with "Commodity Currencies" have been given more attentions, and evidences have been found that there exists a long-run relationship between the real exchange rate and the real commodity price for commodity-exporting countries ${ }^{1}$ [7], including Australia, Canada, Chile, New Zealand ${ }^{2}$, and South Africa. Similar results are confirmed by Chen and Rogff [8] for Australia, Canada and New Zealand. In addition, Chen [10] found that for three major OECD (The Organization for Economic Cooperation and Development) primary commodity producers (Australia, Canada, and New Zealand), nominal exchange rates exhibit a robust response to movements in prices of their corresponding commodity prices. Chen and Rogff [11] then subsequently identified two countries from the OECD regime-Australia and New Zealand, as the "exceptions to the rule" when considering exchange rate determination and forecasting. They confirm and extend previous findings that for major commodity exporters with market-based exchange rates, the price of their primary commodity exports is an important and robust determinant for the real exchange rates. However, the commodity price itself tells little about subsequent exchange rate movements. But when combining various macroeconomic fundamentals with the commodity price, results suggest that it can help to predict quarterly exchange rate changes, however, no single specification emerges as the clear winner across both countries and time period. Other literatures for selective developed and developing nations looking at the same issue include: Amano and van Norden [12], Gruen and Wilkinson

${ }^{1}$ For countries that are heavily relied on commodity products to gain export earnings, the price movements in the world commodity markets would then be the changes in the relative demands for their corresponding currencies.

${ }^{2}$ For New Zealand in particular, it refers to Luo and Plantier [9], which focuses on the persistence of NZ dollar misalignments relative to PPP. 
[13], De Gregorio and Wolf [14], Chinn and Johnston [15], and Montiel [16]. However, none was able to offer conclusive evidence to answer why these commodity currencies are unique and may require further investigation. Therefore, our study serves to answer these questions.

Australia and New Zealand are two open economies in the OECD regime. They both share a number of distinctive features in economic structures and policy settings. These special features have made the two nation's currencies demonstrate a remarkable strong "commodity currency phenomenon" and to stand out among other commodity currencies ${ }^{3}$. Australia is an export-oriented economy, whose exports in primary commodity products take a significant portion of their gross domestic production. Characterized by mainly mineral (or "hard") commodity exporting, the primary commodity products exported by Australia include iron ore, metallurgical coal, thermal coal, gold and various other metal products. These non-energy products, along with other commodities account for more than $60 \%$ of Australian total exports. New Zealand, in contrast, its exports are heavily dependent on agricultural products such as dairy products, wools, meats and other "soft" commodities. Commodity products exporting contribute about $67 \%$ of its total exports in the late 80 s. Primary commodity products still take about $50 \%$ of New Zealand's total exports today. Moreover, New Zealand is a well-known key player of its commodity products in the global market, in spite of its relatively small economy. It supplies nearly $50 \%$ of the total world exports of lamb and mutton where only a fraction of less than $20 \%$ of its meat production is consumed domestically. Given both countries are heavily dependent on commodity products to gain export earnings, the price movement in world commodity market would then have an impact on the relative demand for the corresponding currency. Neither of the two countries is big enough to influence the world market, they both also have adopted a sufficiently long period of a floating exchange rate regime under the inflation targeting system $^{4}$, central banks normally have very limited controls and interventions over exchange rate movements. Commodity price fluctuations can then essentially represent a source of exogenous shocks to their terms-of-trade, which eventually channel up and trigger the exchange rate responses. Therefore, the introduction of the country-specific commodity prices indices in Australia and New Zealand's commodity exporting in early 1980s, has offered an opportunity to identify and measure exchange rate fluctuations using these indices.

Motivated by Chen and Rogff [8] [11] studies, we try to investigate if movements in commodity prices can explain the fluctuation in exchange rates. We develop an exchange rate forecasting model by putting the commodity price into the structural forecasting model and to examine if this improves the accuracy of

${ }^{3}$ Cashin, Cespedes, and Sahay [7] have classified 58 countries as the "commodity economies" that have a significant commodity dependency. In addition to Australia and New Zealand, these countries include Finland, Iceland, Norway, and numerous other developing countries.

${ }^{4}$ Australia and New Zealand abandoned their exchange rate pegs in 1983 and 1985, respectively, as part of the economic reform efforts to revitalize their domestic economies. Moreover, around 1990 they also adopted some variant of inflation-targeting monetary policy [8]. 
exchange rate forecasting. A three-step process is followed in this paper: firstly, we test if the country-specific commodity price index has explanatory power when modelling exchange rates movements in Australia and New Zealand. Our results indicated that the country-specific commodity price index does have some explanatory power and our results are robust. We therefore conclude that the commodity price index should be considered as one of the determinants when forecasting exchange rates. Secondly, we use the cross-rate between Australian Dollar and New Zealand Dollar to examine the relationship between the cross rate and the commodity price. Results indicate that the commodity price offer an exceptional explanatory power when forecasting the cross-exchange rate movements. Thirdly, once including commodity prices index into the forecasting model, the forecasting performance of the modified model can be evaluated both in-sample and out-of-sample against a simple random walk model. Our results suggest a remarkable in-sample forecasting performance. For out-of-sample forecasts, the modified exchange forecasting model is also able to provide more consistent forecasting performance than the benchmark random walk model. Therefore, our study contributes to the existing literatures that the commodity price is an important determinant of the current exchange rate and the future exchange rate movements in Australia and New Zealand.

\section{Commodity Price Indices in Australia and New Zealand ${ }^{5}$}

Figure 1 and Figure 2 below present a graphical view of the relationship between

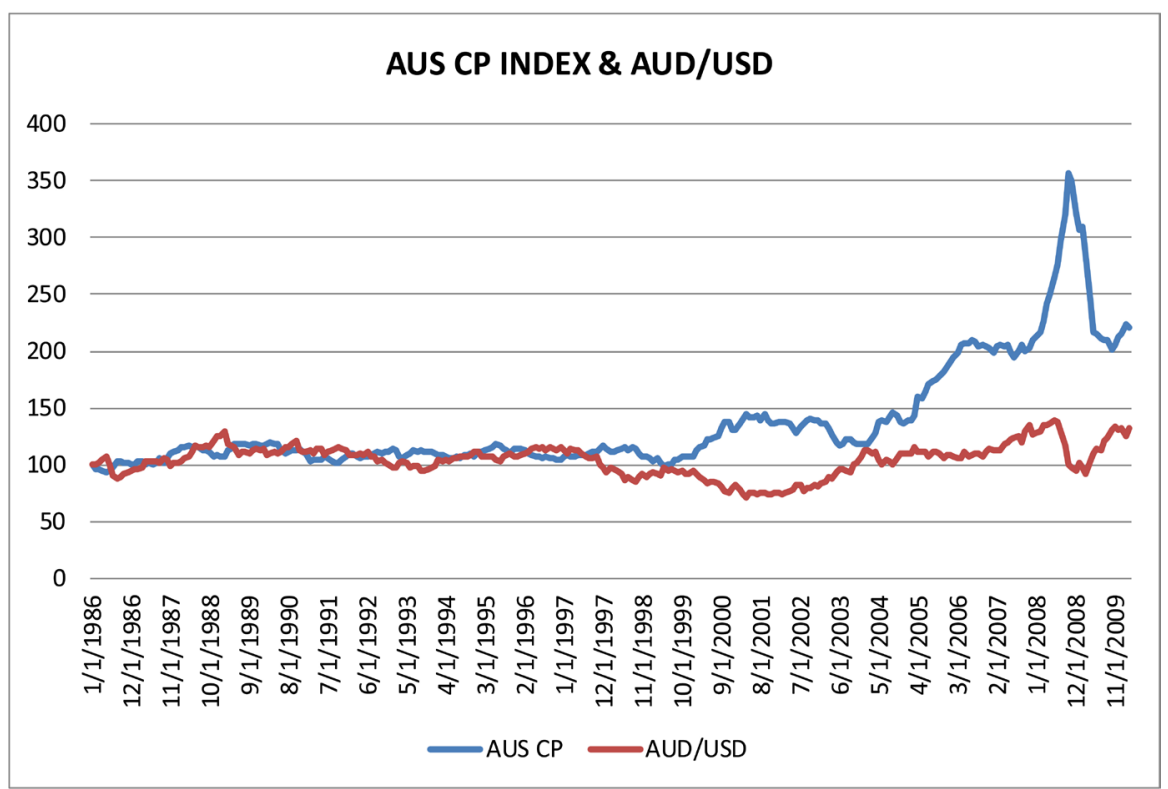

Figure 1. Relationship between the Australian Commodity Price and the Value of Austrian Dollar. Figure 1 illustrates the relationship between the Australian commodity price and the value of Australian Dollar from 1986 to 2010, the base level is set at 100 as of January 1986.

${ }^{5}$ See Appendix A for more information about the commodity indices in Australia and New Zealand. 


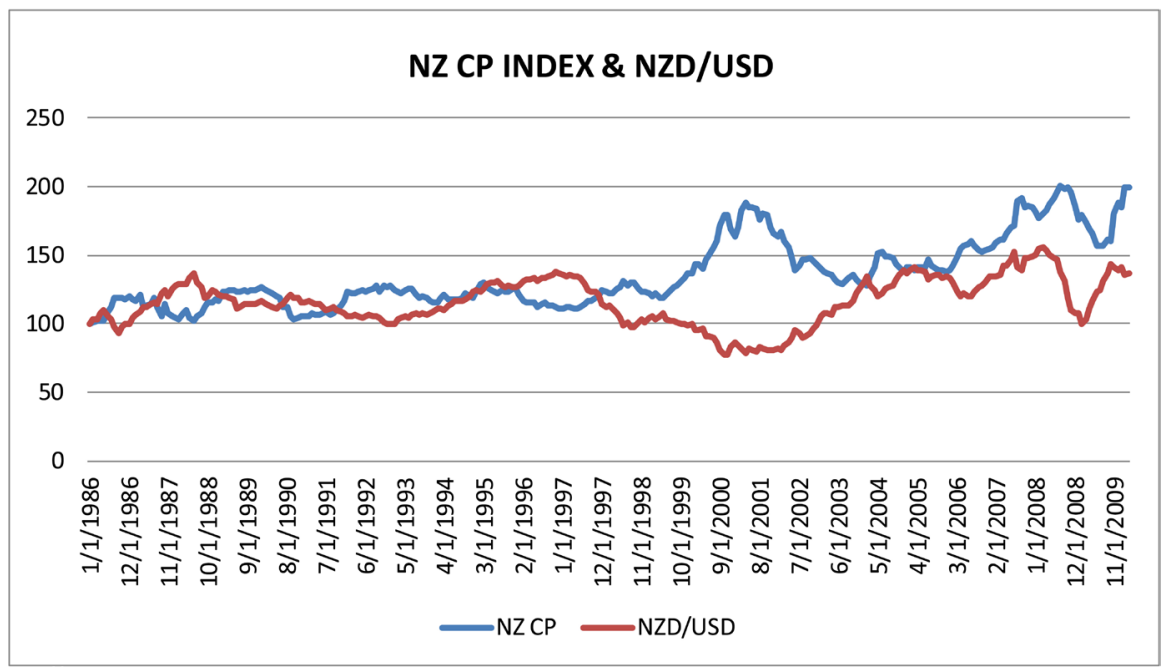

Figure 2. Relationship between the NZ Commodity Price and the Value of NZ Dollar. Figure 2 illustrates the relationship between the NZ commodity price and the value of New Zealand Dollar from 1986 to 2010, the base level is set at 100 as of January 1986.

Australian and New Zealand commodity price index and their corresponding quoted exchange rate against US dollar from 1986 to 2010, respectively. The commodity index is the monthly time series and its base value is set at 100 as of $1^{\text {st }}$ January 1986.

In Figure 1, we observe that the Australian commodity price and the AUD/USD exchange rate appear to have an inverse relationship. This suggests that when the commodity price is moving up, the AUD/USD exchange rate is going down. Thus, Australian dollar is appreciating when the Australian commodity price goes up. This implies that the value of the Australian dollar is moving in line with prices of its commodity exporting. Similar pattern is observed from Figure 2 for New Zealand. The New Zealand commodity price index also appears to have an inverse relationship with the value of its currency, especially after late $1990 \mathrm{~s}^{6}$.

Figure 3 below illustrates the relationship between Australian and New Zealand commodity price indices. The nature of the underlying commodities which two indices represent is fundamentally different. However, the commodity prices in Australia and New Zealand are having a high level of co-movements from mid 1980s to early 2000s. From late 1990s to 2004, the price of New Zealand soft commodities enjoyed a relatively higher growth rate compared to Australian commodity prices. However, with the increasing demand for metal products from developing countries (China in particular) and global economic expansions, Australia has enjoyed the rapid growth in their commodity prices since 2005.

Previous studies have found that some economics models, i.e. PPP, UIP, can only provide valid information when forecasting exchange rates in the long run. Results from these models usually are not better than a simple random walk

${ }^{6}$ Please see Cashin, Cespedes and Sahay [7] for more details. 


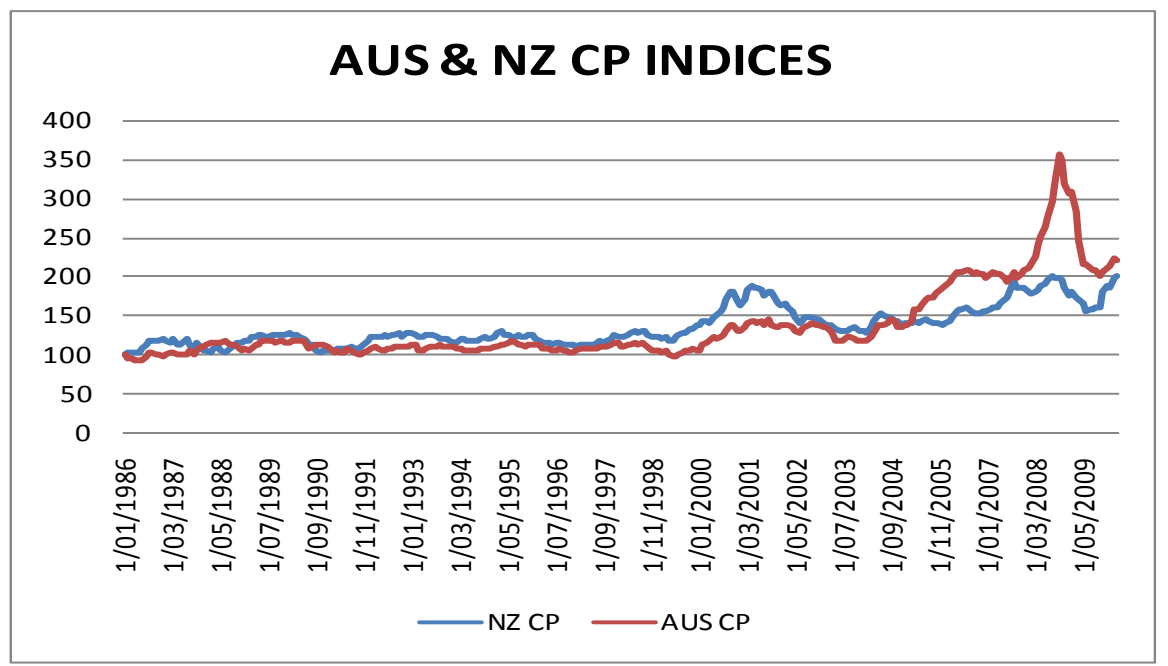

Figure 3. Relationship between NZ and Australian Commodity Prices. This figure illustrates the relationship between the commodity price in Australia and New Zealand over time, the base level is set at 100 as of January 1986 for both countries.

model. Since the term "Commodity Currency" has been introduced and brought to the attention of international finance, researchers have found some promising evidences that commodity price may play some roles in determining and forecasting exchange rates ${ }^{7}$. A recent study by Luo and Plantier [9] has estimated the half-life of NZD/AUD cross rates deviation is about 0.6 years (the time it takes for actual exchange rate to return to its theoretical fundamental value, in this case its PPP value). Whereas a study conducted by Chen and Rogoff [8] reports a more than 1.6 years half-life for the NZD/USD pair and an average of 3 to 5 years reported for various pairs of the commodity currencies in simple PPP-based regression models.

If a random walk is what the exchange rate movement follows, then effects of innovations on the exchange rate are highly persistent and the time series can fluctuate without bounds [7]. Figure 4 below presents the exchange rate behaviour of NZD/AUD cross rate from 1991 to 2010. The graph indicates that the actual exchange rate moves within the $10 \%$ bounds of its "Fair value" ity of the sample period. Moreover, there is a clear tendency of the actual crossexchange rates to return to their long-term "Fair Value" over time. Since the "Fair Value" is usually determined by fundamental macroeconomic variables, it is therefore reasonable to believe that NZD/AUD cross rates may be predicted if shocks are identified and included into an exchange rate forecasting model with possible structural breaks.

In Figure 4, the NZD/AUD long-term "Fair Value" (or the long-term "Equilibrium Value") is within the 0.8 and $0.85 \mathrm{NZ}$ dollar per Australia dollar range in the past 20 years. The actual exchange rates, on the other hand, fluctuate from as

${ }^{7}$ For more comprehensive background information and empirical evidences, see Chen [10], Chen and Rogoff [11], Chen, Rogoff and Rossi [17].

${ }^{8}$ The fair value is defined as the exchange rate that would be predicted according to PPP and UIP, as illustrated by Equation (11). 


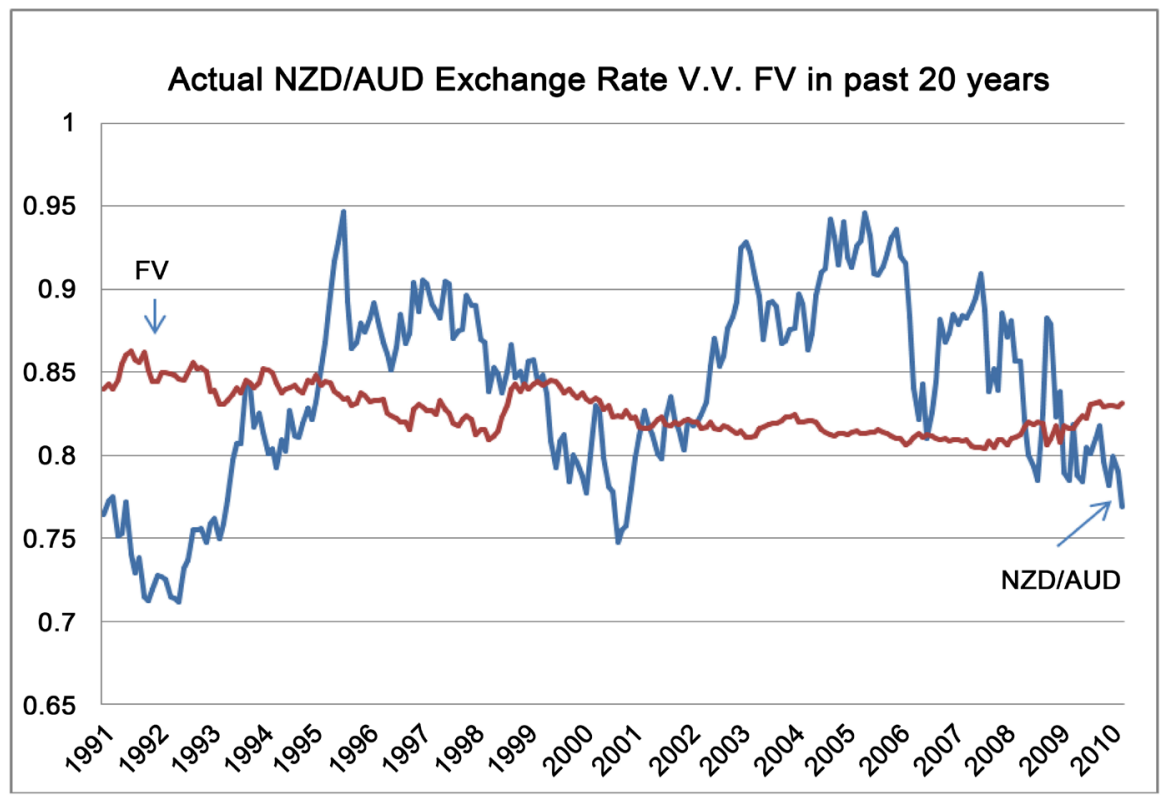

Figure 4. The NZD/AUD Exchange Rate and the Corresponding "Fair Value". This figure illustrates the NZD/AUD cross exchange rate over time. It also presents the "Fair Value' of the cross rate determined by fundamental macroeconomic variables. The horizontal axis represents the value of New Zealand dollar per Australian dollar.

high as 0.7 around 1992 to as low as 0.95 in 1995 and 2005. In addition, the fair value appears to be relatively constant overtime and failed to pick up any major 'break' of actual exchange rate movements. The lacking correlation between the nominal exchange rate and its underlying long-term equilibrium value from existing literatures may be due to the fact that many attempted to model movements of nominal exchange rates using long-term equilibrium value as the explanatory variable. Therefore, in our model, we propose to use the "departure from currency's long-term equilibrium value" (the difference between the nominal exchange rate and its long-term equilibrium value) rather than the long-term equilibrium value itself. This makes our methodology superior to previous studies.

\section{Data Descriptions}

The exchange rate and the commodity price index are monthly time series for the period from 1986 to 2010. Data are obtained from three sources: Federal Reserve of the U.S., DataStream database and the Reserve Bank of Australia. The Australian and New Zealand direct exchange rates against the US dollar are monthly mid-rate and obtained from the Federal Reserve Bank of the United States. The cross exchange rates between AUD and NZD are fixed at 4:00 p.m. (6:00 GMT) and loaded at approximately 4:30 p.m. (6:30 GMT) for daily records. The monthly series is the mid-point determined by the Reserve Bank of Australia on the basis of quotations in the Australian Foreign Exchange market (Source: Reserve Bank of Australia).

The commodity price indices used in this study are the country-specific indi- 
ces of commodity export prices. These indices are constructed in a way to reflect the specific characteristics of the respective country's commodity trading with the rest of the world. The CBA NZ Commodity Price Index and The RBA Commodity Index SDR are the two commodity price indices for New Zealand and Australia. They were developed by the Commonwealth Bank of Australia (CBA) and The Reserve Bank of Australia (RBA) in 1980s. For the US, we use $S$ \& P GSCI Non-Energy Spot Price Index'. There are other indices potentially can be used as well. These include, the price of individual primary commodities, terms of trade indices and aggregate (non-country-specific) indices of commodity-price. The country-specific commodity exports price index is used due to the following reasons. Firstly, neither New Zealand nor Australia has the export price of a single commodity can well mirror the movements of overall commodity-export prices. Secondly, terms-of-trade indices could be affected not only by the composition of the country's exports but also the composition of the country's GDP. This is because terms-of-trade indices are typically calculated using exports and unit values. Thirdly, prices of individual commodities do not tend to move together on global-commodity-markets; the movements in aggregate commodity-price indices are likely to be a poor proxy of movements compared to the country-specific commodity export prices [7].

\section{Theoretical Framework and Methodology}

Purchasing Power Parity (PPP) states a relationship between the nominal exchange rate and the inflation (price level) differences between two countries. Such a relationship can be expressed in a basic form as the following:

$$
S_{t}=P_{t}^{\text {country A }}-P_{t}^{\text {country B }}+\varepsilon_{t}
$$

where $S_{t}$ is the nominal exchange rate; $P_{t}$ is the price level, both in logarithm forms. Equation (1) simply defines that the change of the exchange rate can be approximated by the difference of the price levels between two counties and the purchasing power parity holds to a certain degree of error.

The Uncovered Interest Parity (UIP) condition gives an approximation that:

$$
E_{t}\left(S_{t+1}\right)=S_{t}+\left(i_{t}^{\text {country A }}-i_{t}^{\text {country B }}\right)
$$

where $i$ is the nominal interest rate; $E_{t}$ represents the expected spot exchange rate at time $t$. Notes this setting is only valid under the risk-neutral assumption. If we relax this assumption and we get Equation (3):

$$
E_{t}\left(S_{t+1}\right)=S_{t}+i_{t}^{\text {country A }}-i_{t}^{\text {country B }}+R P_{t}
$$

where $R P$ is the risk premium on country A's interest bearing assets over country B's assets. As expectations are not necessarily rational, we therefore rearrange

\footnotetext{
${ }^{9}$ As in Chen and Rogoff [8], we focus only on non-energy commodity due to its underlying economics complexity. In addition, for non-economic-related causes, such as international security concerns, often contribute to both global energy price and currency fluctuations, and are likely to complicate interpretations. This may potentially explain in part why higher energy prices, at times, appear to lead to a depreciation of the currency relative to the US dollar.
} 
Equation (3) as following:

$$
S_{t}=E_{t}\left(S_{t+1}\right)+\left(i_{t}^{\text {country B }}-i_{t}^{\text {country A }}-R P_{t}\right)
$$

Equation (4) differs from Equation (2) as it takes into consideration of the risk premium that the investor seeks in order to be willing to hold foreign assets. Equation (4) can be carried forward for the infinite future and can then be presented as: the current exchange rate equals the current interest rate differentials subtracted from the current risk premium and plus the future expected exchange rate. For example, the term $S_{t}$ can be further expressed as following:

$$
S_{t+1}=\left(i_{t+1}^{\text {country B }}-i_{t+1}^{\text {country A }}-R P_{t+1}\right)+E_{t+1}\left(S_{t+2}\right)
$$

$S_{t+2}$ then can be further expressed as:

$$
S_{t+2}=\left(i_{t+2}^{\text {country B }}-i_{t+2}^{\text {country A }}-R P_{t+2}\right)+E_{t+2}\left(S_{t+3}\right)
$$

We therefore derive the following equation:

$$
S_{t}=i_{t}^{\text {country B }}-i_{t}^{\text {country A }}-R P_{t}+\sum_{K=1}^{\infty} E_{t+k}\left(i_{t+k}^{\text {country B }}-i_{t+k}^{\text {country A }}-R P_{t+k}\right)+E_{t}\left(S_{\infty}\right)
$$

The term $S_{\infty}$ above can be represented by the PPP condition as Equation (1) and prevail in the infinite future under the assumption that there was no interest rate differential between two counties. In this case $S_{\infty}$ can be expressed as:

$$
S_{\infty}=P_{\infty}^{\text {country A }}-P_{\infty}^{\text {country B }}+\varepsilon_{\infty}
$$

Furthermore, we can then express the expected future PPP exchange rate as the sum of the current (today's at time $t$ ) PPP exchange rate plus the sum of future expected inflation rate differentials and any expected changes of $\varepsilon_{\infty}$ :

$$
S_{\infty}=P_{t}^{\text {country A }}-P_{t}^{\text {country B }}+\varepsilon_{t}+\sum_{K=1}^{\infty} E_{t+k}\left(\Delta P_{t+k}^{\text {country B }}-\Delta P_{t+k}^{\text {country A }}+\Delta \varepsilon_{t+k}\right)
$$

If we substitute Equation (9) into Equation (7) and rearrange the equation, we can then derive the current exchange rate $S_{t}$ :

$$
\begin{aligned}
S_{t}= & \left(i_{t}^{\text {country B }}-i_{t}^{\text {country A }}\right)+\left(P_{t}^{\text {country A }}-P_{t}^{\text {country B }}\right)-\left(R P_{t}+\varepsilon_{t}\right) \\
& +\sum_{K=1}^{\infty} E_{t+k}\left(i_{t+k}^{\text {country B }}-i_{t+k}^{\text {country A }}-R P_{t+k}\right) \\
& +\sum_{K=1}^{\infty} E_{t+k}\left(\Delta P_{t+k}^{\text {country A }}-\Delta P_{t+k}^{\text {country B }}+\Delta \varepsilon_{t+k}\right)
\end{aligned}
$$

Equation (10) above represents a dynamic relationship between two countries' exchange rates, interest rates and price levels (inflation). The spot exchange rate is dependent on a number of observable factors as well as various unobservable factors. We define observable factors (interest rates and price levels in Equation (10)) as the "Fair Value" described in Equation (11) below:

$$
\text { Fair Value }=\left(i_{t}^{\text {country B }}-i_{t}^{\text {country } \mathrm{A}}\right)+\left(P_{t}^{\text {country A }}-P_{t}^{\text {country B }}\right)-(\overline{R P}+\bar{\varepsilon})
$$

All data are monthly and in logarithm forms except the average risk premium. 
$i_{t}$ is the monthly average one-year interbank swap rates ${ }^{10}$ from Jan 1986 to Mar 2010. $P_{t}$ is the logarithm form of monthly CPI over the same period, $\overline{R P}$ is the average risk premium between the two countries, in this case, the difference in the interest rates. The term $\bar{\varepsilon}$ is serving as a normalization factor.

We calculate the term "Departure from Fair Value" by subtracting Equation (11) from Equation (10) and arrives at the following reduced form:

$$
\begin{aligned}
& \text { Departure from Fair Value }=(\overline{R P}+\varepsilon)-\left(R P_{t}+\varepsilon\right) \\
& \sum_{K=1}^{\infty} E_{t+k}\left(i_{t+k}^{\text {country B }}-i_{t+k}^{\text {country A }}-R P_{t+k}\right)+\sum_{K=1}^{\infty} E_{t+k}\left(\Delta P_{t+k}^{\text {countryA }}-\Delta P_{t+k}^{\text {country } B}+\Delta \varepsilon_{t+k}\right)
\end{aligned}
$$

Define "Error" as the departure of the actual exchange rate from its long term fair value at time t, derive from Equation (12), we then use the following regression specification to examine the relationship between 'Error' and the following independent variables:

$$
\begin{aligned}
\text { Error }_{t}= & \alpha_{t}+\beta_{1}\left(\text { Error }_{t-1}\right)+\beta_{2} \Delta\left(\text { Error }_{t-1}\right)+\beta_{3} \Delta\left(\text { Ral.GDP }_{t-3}\right) \\
& +\beta_{4} \Delta\left(\text { Comm.Pr }_{t-1}^{\text {country A }}\right)+\beta_{5} \Delta\left(\text { Comm.Pr }_{t-1}^{\text {country B }}\right)+\varepsilon_{t}
\end{aligned}
$$

Data in Equation (13) are monthly data and in logarithm forms except the relative GDP which is the logarithm difference between two underlying countries' GDP growth rates and the data is quarterly. $\alpha_{t}$ is the constant term. $\beta\left(\right.$ Error $\left._{t-1}\right)$ is the momentum term, where if the exchange rate appreciates in one month, it is more likely to continues the appreciation in the subsequent month, $\beta \Delta\left(\right.$ Error $\left._{t-1}\right)$ represents the reversion-to-fair-value term, where it captures the tendency of currency value reverse back towards its long term fair value over time ${ }^{11} . \quad \beta \Delta\left(\right.$ Ral.GDP $\left._{t-3}\right)$ captures the effects of the difference in relative GDP growth rates between two underlying countries. Notes it is lagged 3 months as the GDP data is quarterly other than monthly. $\beta \Delta\left(\operatorname{Comm} P r_{t-1}\right)$ captures the change of commodity prices.

In order to estimate significant shocks that cause the "Error" (the "departure" from the fair value), we take a reduced-form approach by adopting a general-to-specific search among potential variables that may have an impact on the currency value. We investigate a few macroeconomic variables that are relevant and significant both economically and statistically in determining the nominal value of NZD/AUD cross exchange rate. The specification for approximating NZD/AUD cross exchange rate is marginally different from the specification for NZD/USD and AUD/USD exchange rates estimations. This is due to differences in economic structures, policy marking and government regulations between Australia, New Zealand and the U.S. Therefore, impacts from shocks on under${ }^{10}$ The selection of representative interest rate has taking into considerations of the fact that normally the short-term interest rate variation is often anticipated by the market, and any fully anticipated monetary policy on the interest rate changes should not affect the value of exchange rate. Moreover, we have realized that a longer term interest rate maybe even better, after considering other factors, i.e. data availability and liquidity (particularly in NZ market), one-year interbank swap rate was chosen.

${ }^{11}$ The momentum term and the reversion-to-fair-value terms in equation 13 represent "overshooting" effects in exchange rate dynamics. 
lying exchange rates may differ substantially. Specifically, we examine how do fluctuations in country-specific commodity prices translate into movements in the exchange rate? We give special emphasis on the determination of NZD/AUD cross-exchange-rate and the importance of its corresponding commodity prices. To illustrate this, we modify equation 13 as follows:

$$
\begin{aligned}
\text { Error }_{t}= & \alpha_{t}+\beta_{1}\left(\text { Error }_{t-1}\right)+\beta_{2} \Delta\left(\text { Error }_{t-1}\right)+\beta_{3} \Delta\left(\text { Ral.GDP }_{t-3}^{N Z \& A U}\right) \\
& +\beta_{4}\left(\text { NZ.ComPr }_{t-1}\right)+\beta_{5}\left(\text { AU.ComPr }_{t-1}\right)+\beta_{6}\left(\text { Migration }_{t-1}^{N Z}\right)+\varepsilon_{t}
\end{aligned}
$$

The above specification follows an error-correction framework; it is conducted in a way that ensures the consistency of the robustness relationship of dependent variables with the exchange rate. The equation, therefore, established to estimate coefficients that are not sensitive to minor variations for the chosen sample period.

\section{Results and Discussion}

\subsection{Regression Results}

Table 1 below reports parameter coefficients and corresponding t-statistics from Equation (14), three models have been estimated using NZD/AUD, NZD/USD and AUD/USD exchange rates as dependent variables. Results are remarkably consistent across all currency pairs. First, the effects of momentum and commodity prices movements are uniformly strong and consistent in all three specific models. Second, majority of coefficients from respective regression models are in the theoretically correct sign and are statistically significant, with only two exceptions which is the US commodity price and the GDP change between US and New Zealand. Third, there is no evidence to support the significance of US commodity prices that could be related to the movements of either the NZD/USD or the AUD/USD exchange rate dynamics. Therefore, these results confirm the hypothesis that Australian and New Zealand commodity prices should be applied to measure the exchange rate movement. In addition, results indicate that when putting macroeconomic variables into the regression model, the NZD/AUD cross rate model does provide superior results than others.

In Table 1 the momentum coefficients are positive and ranging from 0.94 to 0.98 across all models, indicating a strong momentum effect in exchange rate movements. The New Zealand commodity price coefficient in NZD/AUD cross rate model is negative and statistically significant at the $1 \%$ level, indicating a negative relationship between corresponding commodity price dynamics and the currency deviation from its long-term fair value. This negative relationship suggests that an increase in NZ commodity price may decrease the error, therefore result an appreciation of New Zealand dollar. The coefficient for Australian commodity price is positive and statistically significant at the $1 \%$ level, indicating that there exists a positive relationship between the Australian commodity price and the error, with increasing of Australian commodity price, the error increases, thus, Australian dollar appreciate in value. 
Table 1. Exchange Rates and Commodity Prices Dynamics: General to Specific Models. This table reports coefficients and t-statistics from Equation (14). We conduct both the "general" model (Columns 2, 4 and 6) and the 'specific model (columns 3, 5 and 7). We eliminate variables that are insignificant from the "general" model until all remaining variables are significant in the "specific" model. The dependent variable is the actual exchange rates between NZD/AUD, AUD/USD and NZD/USD. The corresponding t-statistics are reported in parentheses. All variables are in logarithm forms. We have included NZ Migration as an explanatory variable because of the general-to-specific search indicated that it is statistically significant. The relative GDP is lagged for three periods as GDP data is quarterly. ${ }^{\star},{ }^{\star \star}$ and ${ }^{\star *}$ indicate statistical significant at the $10 \%, 5 \%$, and $1 \%$ level, respectively.

\begin{tabular}{|c|c|c|c|c|c|c|}
\hline \multirow{2}{*}{$\begin{array}{c}\text { Variables } \\
\text { Momentum }\end{array}$} & \multicolumn{2}{|c|}{ NZD/AUD } & \multicolumn{2}{|c|}{ AUD/USD } & \multicolumn{2}{|c|}{ NZD/USD } \\
\hline & $0.9429^{\star \star \star}$ & $0.9521^{\star \star \star}$ & $0.9867^{\star * *}$ & $0.9849^{\star *}$ & $0.9822^{\star * \star}$ & $0.9789^{\star * \star}$ \\
\hline & $(-55.809)$ & $(-56.805)$ & -70.463 & $(-72.490)$ & $(-73.800)$ & $(-74.520)$ \\
\hline \multirow[t]{2}{*}{ Mean Reversion } & $-0.1521^{\star \star}$ & $-0.1301^{\star \star}$ & -0.0751 & & -0.0579 & \\
\hline & $(-2.437)$ & $(-2.077)$ & $(-0.957)$ & & $(-0.794)$ & \\
\hline \multirow[t]{2}{*}{ Ral.GDP.NZ\&AU } & $0.1876^{* *}$ & $0.1890^{* *}$ & & & & \\
\hline & $(-2.187)$ & $(-2.178)$ & & & & \\
\hline \multirow[t]{2}{*}{ Ral.GDP.AU\&US } & & & $0.3733^{*}$ & $0.3749^{* *}$ & & \\
\hline & & & $(-1.955)$ & $(-1.976)$ & & \\
\hline \multirow[t]{2}{*}{ Ral.GDP.NZ\&US } & & & & & 0.1205 & \\
\hline & & & & & $(-1.304)$ & \\
\hline \multirow[t]{2}{*}{ NZ Commodity Prices } & $-0.1977^{\star * *}$ & $-0.2099^{* * *}$ & & & $-0.2192^{\star * *}$ & $-0.2131^{\star * *}$ \\
\hline & $(-3.560)$ & $(-3.748)$ & & & $(-3.923)$ & $(-4.583)$ \\
\hline \multirow[t]{2}{*}{ AU Commodity Prices } & $0.1906^{* * *}$ & $0.1798^{\star \star \star}$ & $-0.3326^{* * *}$ & $-0.2994^{\star * *}$ & -- & \\
\hline & $(-3.771)$ & $(-3.526)$ & $(-5.323)$ & $(-5.995)$ & & \\
\hline \multirow[t]{2}{*}{ US Commodity Prices } & & & 0.0423 & & 0.0030 & \\
\hline & & & $(-0.9828)$ & & $(-0.078)$ & \\
\hline \multirow[t]{2}{*}{ NZ Migration } & $0.0000^{\star * *}$ & & & & & \\
\hline & $(-2.727)$ & & & & & \\
\hline Adj. R-squared & 0.9293 & 0.9276 & 0.9485 & 0.9486 & 0.9543 & 0.9515 \\
\hline Sample period & 1986M1-2010M1 & 1986M1-2010M1 & 1986M1-2010M1 & 1986M1-2010M1 & 1986M1-2010M1 & 1986M1-2010M1 \\
\hline No. obs. & 291 & 291 & 291 & 291 & 291 & 291 \\
\hline Durbin-Watson & 2.0057 & 1.9823 & 1.9336 & 1.9903 & 1.9181 & 2.0135 \\
\hline
\end{tabular}

The coefficients for mean reversion and the relative GDP growth in Table 1 are statistically significant at the 5\% level for the NZD/AUD cross rate model (for both "general" and "specific" specifications). However, in NZD/USD models, there are no statistical evidences which support the existence of either the mean reversion effect or the effect of relative GDP growth. For AUD/USD models, the effect of relative GDP growth between Australia and the US is statistically significant at the $10 \%$ level in the "general" model, and at the $5 \%$ significant level in the "specific" model. We also put the "Net Migration" variable to measure the effect of New Zealand Net Migration to Australia. The Net Migration coefficient is statistically significant at the $1 \%$ level in the NZD/AUD cross rate model. One 
possible explanation is that the flow of migrant funds may affect supply and demand of both currencies, hence the net effect of migration is expected to play an active role in determining the cross-exchange rate dynamic ${ }^{12}$. Munroe [18] found that "migration flows (between New Zealand and Australia) have an outsized effect on the housing market, which causes large flows of funds, and affect the exchange rate indirectly via interest rates". Despite the fact that New Zealand net migration towards Australia is a statistically significant variable in the model, we excluded it from our further analysis as it is deemed to be economically insignificant because the coefficient is 0.0000019 .

\subsection{Regression Models with Structural Breaks}

We now turn to examine possible structural breaks during our sample period. Two possible structural breaks are chosen to reflect two most recent major financial crises; early 2001 and late 2007. We simply give the time-dependent dummy variable a value of "one" for the period before the break date and a value of "zero" for the period after the break date. Results in Table 2 and Table 3 suggest that coefficients of time dependent variable provide relatively little evidence of any structural break. We therefore conclude that we may have some possible small parameter shifts for the sample period, and the expected sign and magnitude of coefficients are stable over the entire sample period without systematic structural breaks. We now turn to explore in-sample and out-of-sample forecasting performances for the NZD/AUD cross rate model.

\subsection{In-Sample and Out-of-Sample Forecasting13}

In this section, the following regression equation is going to be used to perform the in-sample forecasting for NZD/AUD cross rate:

$$
\begin{aligned}
\text { Error }_{t+k}= & \alpha+\beta_{1}\left(\text { Error }_{t+k-1}\right)+\beta_{2} \Delta\left(\text { Error }_{t+k-1}\right)+\beta_{3} \Delta\left(\text { Ral.GDP }_{t+k-3}^{N Z \& A U}\right) \\
& +\beta_{4}\left(\text { NZ.ComPr }_{t+k-1}\right)+\beta_{5}\left(\text { AU.ComPr }_{t+k-1}\right)+\varepsilon_{t+k}
\end{aligned}
$$

Figure 5 below presents the performance of the commodity-price-augmented regression model we developed for forecasting NZD/AUD cross exchange rate movements (Equation 15). It provides us a visual observation for the in-sample NZD/AUD cross rate forecasting test ${ }^{14}$. We include results from a random walk model and the actual NZD/AUD cross market exchange rate. All parameters are estimated using data from January 1986 to January 2010. The movement of the blue-line (representing the in-sample one-month-ahead forecasted NZD/AUD cross exchange rates) is remarkably close to the red line (the actual NZD/AUD market cross exchange rate). This indicates an excellent in-sample forecasting of our NZD/AUD cross rate model. This model not only picks up every major

\footnotetext{
${ }^{12}$ According to Statistic NZ, the biggest destination for New Zealand emigrants is by far its best neighbor-Australia. Moreover, Australia is the second in line among the countries that listed as the biggest source of New Zealand's immigrants with account for $20 \%$ of all migrant arrivals.

${ }^{13}$ See Appendix B for an illustration of the out-of-sample forecasting in details.

${ }^{14}$ In-sample forecasting period is from the $1^{\text {st }}$ month of year 1986 to $1^{\text {st }}$ month of 2010 , of which 219 observations are included.
} 
trends of the exchange rate movement in past two decades, but also accurately measures exchange rate turning point, represented by peaks and troughs in Figure 5. Results from the Random Walk (RW) model (represented by the green line) show no signs of any predictability of actual NZD/AUD cross rates over the entire sample period. From early 1987 to the beginning of 1991, the Random Walk model completely mis-specified the underlying exchange rate movement. The Random Walk model also underestimates the volatility of NZD/AUD cross rate over time. It offers no prediction of the changes of direction on the currency movement after 1991.

However, despite the superiority of our NZD/AUD cross rate in-sample forecasting model, it is necessary for us to use contemporaneous data when conducting such estimates. Therefore, an out-of-sample forecast performance test is to be conducted. For out-of-sample forecasting, we first adopt standard quantitative procedures involved in forecasting the departure from the fair value from Equation (12), where the forecasting errors are defined as: $F E_{t+k}=S_{t+k}-\widehat{S_{t+k}}$, where $k \geq 1$ and $S_{t+k}$ represents the k-step-ahead forecast.

We measure forecasting errors for four time intervals, 1-month-ahead,

Table 2. OLS with Possible Structural Break. This table provides the regression results for possible structural breaks with the break point set at January 2001. This break point is selected as at the first month of year 2001 to reflect the most recent major global financial crisis. ${ }^{*}{ }^{* *}$, and ${ }^{* *}$ indicate significance at the $10 \%, 5 \%$, and $1 \%$ levels, respectively.

\begin{tabular}{|c|c|c|c|c|c|c|c|c|c|}
\hline & \multicolumn{3}{|c|}{ NZD/AUD } & \multicolumn{3}{|c|}{$\underline{\text { NZD/USD }}$} & \multicolumn{3}{|c|}{ AUD/USD } \\
\hline & Coefficient & Std. Error & t-Statistic & Coefficient & Std. Error & t-Statistic & Coefficient & Std. Error & $\mathrm{t}$-Statistic \\
\hline $\mathrm{D}^{\star}$ Momentum & -0.0325 & 0.0391 & -0.8293 & 0.0088 & 0.0321 & 0.2750 & 0.0413 & 0.0322 & 1.2839 \\
\hline Mean Reversion & $-0.1301^{\star *}$ & 0.0626 & -2.0769 & -0.0578 & 0.0728 & -0.7944 & -0.0751 & 0.0784 & -0.9574 \\
\hline $\mathrm{D}^{\star}$ Mean Reversion & 0.1199 & 0.1258 & 0.9526 & 0.0585 & 0.1577 & 0.3710 & 0.1583 & 0.1597 & 0.9912 \\
\hline Ral.GDP.NZ\&AU & $0.1890^{\star *}$ & 0.0868 & 2.1770 & & & & & & \\
\hline$D^{\star}$ Ral.GDP.NZ\&AU & $-0.3875^{\star *}$ & 0.1729 & -2.2413 & & & & & & \\
\hline Ral.GDP.AU\&US & & & & & & & $0.3733^{\star *}$ & 0.1909 & 1.9555 \\
\hline Ral.GDP.NZ\&US & & & & 0.1205 & 0.0924 & 1.3043 & & & \\
\hline D*Ral.GDP.NZ\&US & & & & -0.1904 & 0.1973 & -0.9650 & & & \\
\hline NZ Commodity Prices & $-0.2099^{\star * *}$ & 0.0560 & -3.7483 & $-0.2192^{\star * *}$ & 0.0559 & -3.9230 & & & \\
\hline $\mathrm{D}^{\star} \mathrm{NZ}$ Commodity Prices & -0.1672 & 0.1131 & -1.4776 & -0.0269 & 0.1175 & -0.2293 & & & \\
\hline AU Commodity Prices & $0.1798^{\star * *}$ & 0.0510 & 3.5259 & & & & $-0.3326^{\star \star \star}$ & 0.0625 & -5.3230 \\
\hline $\mathrm{D}^{\star} \mathrm{AU}$ Commodity Prices & -0.0300 & 0.1152 & -0.2607 & & & & -0.1171 & 0.1380 & -0.8490 \\
\hline US Commodity Prices & & & & 0.0030 & 0.0386 & 0.0782 & 0.0423 & 0.0431 & 0.9828 \\
\hline $\mathrm{D}^{\star}$ US Commodity Prices & & & & 0.0031 & 0.0817 & 0.0377 & -0.1003 & 0.0885 & -1.1329 \\
\hline Adj. R Square & & 0.9290 & & & 0.9540 & & & 0.9490 & \\
\hline
\end{tabular}


Table 3. OLS with Possible Structural Break. This table provides the regression results for possible structural breaks with the break point set at December 2007. This break point is selected as at the last month of year 2007 to reflect the most recent major global financial crisis. ${ }^{*}{ }^{* *}$, and ${ }^{* *}$ indicate significance at the $10 \%, 5 \%$, and $1 \%$ levels, respectively.

\begin{tabular}{|c|c|c|c|c|c|c|c|c|c|}
\hline & \multicolumn{3}{|c|}{ NZD/AUD } & \multicolumn{3}{|c|}{$\underline{\text { NZD/USD }}$} & \multicolumn{3}{|c|}{$\underline{\mathrm{AUD} / U S D}$} \\
\hline & Coefficient & Std. Error & t-Statistic & Coefficient & Std. Error & $\mathrm{t}$-Statistic & Coefficient & Std. Error & t-Statistic \\
\hline Momentum & $0.9521^{\star \star *}$ & 0.0168 & 56.8054 & $0.9823^{\star \star \star}$ & 0.0133 & 73.7959 & $0.9867^{\star * *}$ & 0.0140 & 70.4635 \\
\hline $\mathrm{D}^{\star}$ Momentum & $-0.4251^{\star * *}$ & 0.1116 & -3.8083 & -0.0700 & 0.0364 & -1.9246 & 0.0576 & 0.0420 & 1.3695 \\
\hline Mean Reversion & $0.1310^{\star *}$ & 0.0626 & -2.0769 & -0.0578 & 0.0728 & -0.7944 & -0.0751 & 0.0784 & -0.9574 \\
\hline $\mathrm{D}^{\star}$ Mean Reversion & 0.1204 & 0.1553 & 0.7753 & $0.4246^{\star *}$ & 0.1928 & 2.2030 & $0.6048^{\star * *}$ & 0.1936 & 3.1237 \\
\hline Ral.GDP.NZ\&AU & $0.1890^{* *}$ & 0.0868 & 2.1770 & & & & & & \\
\hline D*Ral.GDP.NZ\&AU & -0.3100 & 0.3235 & -0.9583 & & & & & & \\
\hline Ral.GDP.AU\&US & & & & & & & $0.3733^{* *}$ & 0.1909 & 1.9555 \\
\hline $\mathrm{D}^{\star R a l . G D P . A U \& U S}$ & & & & & & & 0.4663 & 0.6114 & 0.7627 \\
\hline Ral.GDP.NZ\&US & & & & 0.1205 & 0.0924 & 1.3043 & & & \\
\hline D*Ral.GDP.NZ\&US & & & & -0.4470 & 0.4800 & -0.9312 & & & \\
\hline NZ Commodity Prices & $-0.2099^{* * *}$ & 0.0560 & -3.7483 & $-0.2192^{* * *}$ & 0.0559 & -3.9230 & & & \\
\hline $\mathrm{D}^{\star} \mathrm{NZ}$ Commodity Prices & -0.2205 & 0.1430 & -1.5421 & $0.2731^{* *}$ & 0.1378 & 1.9824 & & & \\
\hline AU Commodity Prices & $0.1798^{\star * *}$ & 0.0510 & 3.5259 & & & & $-0.3326^{* * *}$ & 0.0625 & -5.3230 \\
\hline $\mathrm{D}^{\star} \mathrm{AU}$ Commodity Prices & 0.0941 & 0.1055 & 0.8924 & & & & -0.1637 & 0.1490 & -1.0990 \\
\hline US Commodity Prices & & & & 0.0030 & 0.0386 & 0.0782 & 0.0423 & 0.0431 & 0.9828 \\
\hline $\mathrm{D}^{*}$ US Commodity Prices & & & & -0.1399 & 0.0992 & -1.4114 & $-0.3772^{* * *}$ & 0.1066 & -3.5377 \\
\hline Adj. R Square & & 0.9310 & & & 0.9560 & & & 0.9520 & \\
\hline No. obs. & & 243 & & & 243 & & & 243 & \\
\hline
\end{tabular}

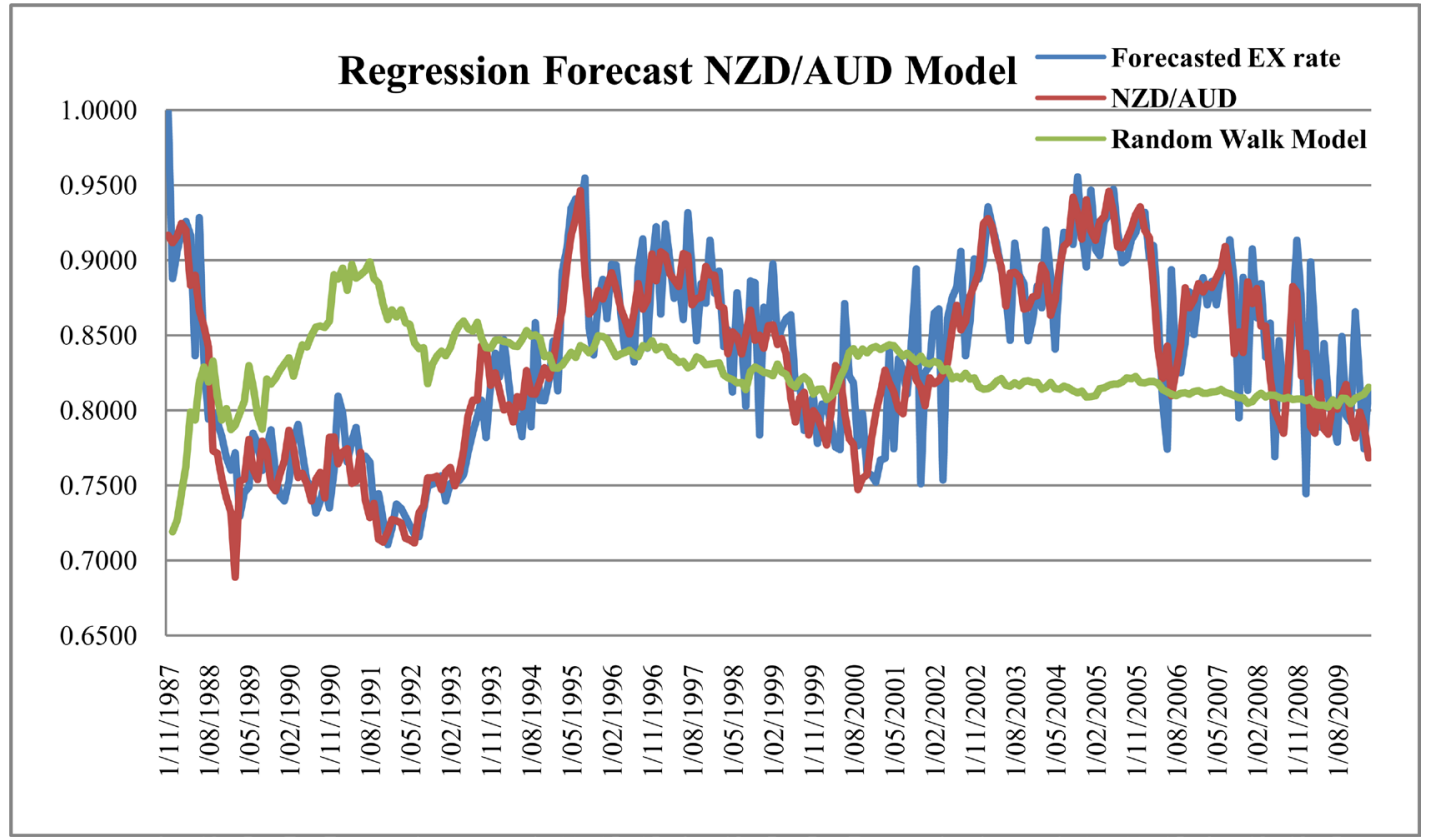

Figure 5. One-month-ahead in-sample regression forecast for NZD/AUD. 
3-month-ahead, 6-month-ahead and 12-month-ahead. The estimation involves the prediction of the long term Fair Value (FV) of NZD/AUD cross rate, this FV is not constant over time. We first need to define the FV before the forecasting error can be derived. To ensure a theoretically sound process of approximating FVs, we apply four methods to predict FVs over the testing time horizon. Firstly, we assume the Fair Value (FV) is known for the out-of-sample period. Hence, FVs are directly taken from the in-sample forecasting models which have been done in the previous section ${ }^{15}$. Secondly, FVs are assumed to be unknown for the out-of-sample period, and are therefore predicted using an AR(1) model, an $\operatorname{ARMA}(1,1)$ model and a random walk model, respectively. To evaluate the forecasting performance, four forecasting measures are applied: Root Mean Square Error (RMSE), Mean Absolute Error (MAE), Mean Absolute Percentage Error (MAPE) and Theil Inequality Coefficient (THEIL).

These measurements offer a set of quantitative values, which specifically measure how far the forecasted fair values are away from the actual observed exchange rates. A lower value indicates a better fit, hence, higher accuracy of the forecasting model. The out-of-sample forecasting involves re-estimating the NZD/AUD cross rate for each historical period, using only data that would have been available to us at that time. Appendix B provides a detailed illustration for a 3-month-ahead out-of-sample forecasting.

Table 4 and Table 5 present forecasting errors for the out-of-sample performance. Results suggest that our commodity price augmented forecasting model remarkably beat the random walk model in every setting under 3- and 6-month testing periods. For 9- and 12-month period, results also suggest that forecasting errors are constantly smaller in most cases. This indicates that our NZD/AUD cross exchange rate forecasting model outperforms the random walk model in majority of the testing time periods. It is necessary to mention that the Random Walk model has been widely considered as the benchmark for exchange rate forecasting models. Based on existing literatures, the Random Walk model works superior compared to other forecasting models. We pick up two sample starting points when conducting out-of-sample forecasting performances: (1) February 1990; and (2) March 1993. These starting points are chosen for the following reasons: New Zealand and Australia both adopted inflation-targeting monetary policy for period between 1990 and 1993. Therefore, it is theoretically sound for future exchange rate forecasting to use the data set available before and after the exchange rate regime shift. In addition to the exchange rate regime shift, the out-of-sample period also spans a period of sharp exchange rate depreciation as well as the sustained appreciation, which began in 1992. Thus, our exchange rate model is believed to better facilitate a more comprehensive model evaluation across the out-of-sample forecasting period. Contrary to previous findings, our fundamental macroeconomic variable exchange rate model has a better forecasting accuracy in short-time horizons (3-month and 6-month) relative to

${ }^{15}$ The in-sample forecasting period is from the $1^{\text {st }}$ month of year 1986 to $1^{\text {st }}$ month of 2010 , which contains entire sample of 219 observations. 
longer time horizons (9-month and 12-month).

\section{Conclusion}

The relationship between the exchange rate and fundamental macroeconomic variables has drawn lots of attentions to many researchers for many years, yet, no clear consensus has been emerged. In this paper, we focus on a set of selective currencies which are considered as the "Commodity Currencies", namely the New Zealand and the Australian dollars. We incorporate commodity prices from these two countries into the exchange rate forecasting model. Results shed extra light on two main issues. Firstly, commodity currencies are not the same across countries. Some are more of "commodity currencies" than others, i.e. more pronounce in New Zealand and Australia than in the U.S. This is due to the fact that

Table 4. Out-of-Sample Forecasting (from Mar. 1993). This table reports Out-of-Sample forecasting performance compared to the Random Walk model. The sample period starts from March 1993 to May 2002, and forecasting period is from May 2002 to January 2010. The evaluation results of RW model are reported in columns 3, 5, 7 and 9 and the "built in" models (Equation (15)) are reported in columns 4, 6, 8 and 10. Root Mean Square Error (RMSE), Mean Absolute Error (MAE), Mean Absolute Percentage Error (MAPE) and Theil Inequality Coefficient (THEIL) offer a set of quantitative values, which specifically measure how far away the model forecasted exchange rates are to the actual exchange rates observed later. A lower value indicates a better fit (higher accuracy) of the tested model. ${ }^{*}$ indicates forecasting superiority over RW model.

\begin{tabular}{|c|c|c|c|c|c|c|c|c|c|}
\hline Method of FV & Horizon & RMSE_RW & RMSE & MAE_RW & MAE & MAPE_RW & MAPE & THEIL_RW & THEIL \\
\hline \multicolumn{10}{|l|}{ In-Sample } \\
\hline & $3 m$ & 0.0341 & $0.0289^{*}$ & 0.0258 & $0.0221^{*}$ & 19.7553 & $16.8073^{\star}$ & 0.1139 & $0.0970^{\star}$ \\
\hline & $6 \mathrm{~m}$ & 0.0422 & $0.0359^{*}$ & 0.0319 & $0.0267^{*}$ & 24.3345 & $20.3970^{*}$ & 0.1436 & $0.1228^{*}$ \\
\hline & $9 m$ & 0.0459 & $0.0406^{*}$ & 0.0351 & $0.0309^{*}$ & 27.1057 & $23.5763^{*}$ & 0.1584 & $0.1412^{\star}$ \\
\hline & $12 \mathrm{~m}$ & 0.0491 & $0.0445^{\star}$ & 0.0381 & $0.0345^{\star}$ & 29.5235 & $26.0723^{*}$ & 0.1727 & $0.1574^{\star}$ \\
\hline \multicolumn{10}{|l|}{$\mathrm{AR}(1)$} \\
\hline & $3 \mathrm{~m}$ & 0.0341 & $0.0309^{*}$ & 0.0258 & $0.0234^{*}$ & 19.7553 & $17.9228^{*}$ & 0.1139 & $0.1036^{\star}$ \\
\hline & $6 \mathrm{~m}$ & 0.0422 & $0.0385^{*}$ & 0.0319 & $0.0285^{*}$ & 24.3345 & $22.0458^{*}$ & 0.1436 & $0.1315^{*}$ \\
\hline & $9 \mathrm{~m}$ & 0.0459 & $0.0435^{\star}$ & 0.0351 & $0.0331^{\star}$ & 27.1057 & $25.6278^{\star}$ & 0.1584 & $0.1508^{\star}$ \\
\hline & $12 \mathrm{~m}$ & 0.0467 & 0.0469 & 0.0359 & 0.0360 & 26.6700 & $26.0377^{\star}$ & 0.1443 & 0.1483 \\
\hline \multicolumn{10}{|l|}{$\operatorname{ARMA}(1,1)$} \\
\hline & $3 \mathrm{~m}$ & 0.0341 & $0.0309^{*}$ & 0.0258 & $0.0234^{*}$ & 19.7553 & $17.9302^{\star}$ & 0.1139 & $0.1036^{*}$ \\
\hline & $6 \mathrm{~m}$ & 0.0422 & $0.0385^{*}$ & 0.0319 & $0.0285^{*}$ & 24.3345 & $22.0642^{*}$ & 0.1436 & $0.1315^{*}$ \\
\hline & $9 m$ & 0.0459 & $0.0435^{\star}$ & 0.0351 & $0.0332^{*}$ & 27.1057 & $25.6551^{\star}$ & 0.1584 & $0.1508^{*}$ \\
\hline & $12 \mathrm{~m}$ & 0.0491 & $0.0476^{*}$ & 0.0381 & $0.0370^{*}$ & 29.5235 & $28.4387^{*}$ & 0.1727 & $0.1674^{*}$ \\
\hline \multicolumn{10}{|l|}{ RW } \\
\hline & $3 \mathrm{~m}$ & 0.0341 & $0.0309^{*}$ & 0.0258 & $0.0233^{*}$ & 19.7553 & $17.7198^{\star}$ & 0.1139 & $0.1038^{*}$ \\
\hline & $6 \mathrm{~m}$ & 0.0422 & $0.0385^{\star}$ & 0.0319 & $0.0282^{*}$ & 24.3345 & $21.5511^{\star}$ & 0.1436 & $0.1321^{\star}$ \\
\hline & $9 \mathrm{~m}$ & 0.0459 & $0.0435^{*}$ & 0.0351 & $0.0328^{*}$ & 27.1057 & $25.0227^{*}$ & 0.1584 & $0.1519^{*}$ \\
\hline & $12 \mathrm{~m}$ & 0.0467 & $0.0467^{*}$ & 0.0359 & $0.0357^{*}$ & 26.6700 & $25.5167^{\star}$ & 0.1443 & 0.1490 \\
\hline
\end{tabular}


Table 5. Out-of-Sample Forecasting (from Feb. 1990). This table reports Out-of-Sample forecasting performance compared to the Random Walk model. The sample period starts from Feb. 1990 to May 2002, and forecasting period is from May 2002 to January 2010. The evaluation results of RW model are reported in columns 3, 5, 7 and 9 and the "built in" models (Equation (15)) are reported in columns 4, 6, 8 and 10. Root Mean Square Error (RMSE), Mean Absolute Error (MAE), Mean Absolute Percentage Error (MAPE) and Theil Inequality Coefficient (THEIL) offer a set of quantitative values, which specifically measure how far away the model forecasted exchange rates are to the actual exchange rates observed later. A lower value indicates a better fit (higher accuracy) of the tested model. * indicates forecasting superiority over RW model.

\begin{tabular}{|c|c|c|c|c|c|c|c|c|c|}
\hline Method of FV & Horizon & RMSE_RW & RMSE & MAE_RW & MAE & MAPE_RW & MAPE & THEIL_RW & THEIL \\
\hline \multicolumn{10}{|l|}{ In-Sample } \\
\hline & $3 m$ & 0.0341 & $0.0297^{\star}$ & 0.0258 & $0.0232^{\star}$ & 19.7553 & $17.7513^{\star}$ & 0.1139 & $0.0986^{*}$ \\
\hline & $6 m$ & 0.0422 & $0.0371^{\star}$ & 0.0319 & $0.0282^{*}$ & 24.3345 & $21.7370^{*}$ & 0.1436 & $0.1249^{*}$ \\
\hline & $9 \mathrm{~m}$ & 0.0459 & $0.0417^{\star}$ & 0.0351 & $0.0325^{\star}$ & 27.1057 & $25.2778^{\star}$ & 0.1584 & $0.1422^{*}$ \\
\hline & $12 \mathrm{~m}$ & 0.0491 & $0.0458^{\star}$ & 0.0381 & $0.0360^{\star}$ & 29.5235 & $28.0641^{\star}$ & 0.1727 & $0.1583^{*}$ \\
\hline \multicolumn{10}{|l|}{$\operatorname{AR}(1)$} \\
\hline & $3 m$ & 0.0341 & $0.0314^{*}$ & 0.0258 & $0.0243^{*}$ & 19.7553 & $18.7275^{\star}$ & 0.1139 & $0.1031^{*}$ \\
\hline & $6 m$ & 0.0422 & $0.0396^{*}$ & 0.0319 & $0.0300^{*}$ & 24.3345 & $23.4934^{*}$ & 0.1436 & $0.1327^{*}$ \\
\hline & $9 \mathrm{~m}$ & 0.0459 & $0.0444^{\star}$ & 0.0351 & $0.0344^{*}$ & 27.1057 & 27.3163 & 0.1584 & $0.1504^{*}$ \\
\hline & $12 \mathrm{~m}$ & 0.0491 & $0.0458^{\star}$ & 0.0381 & 0.1583 & 29.5235 & 30.4585 & 0.1727 & $0.1666^{*}$ \\
\hline \multicolumn{10}{|l|}{$\operatorname{ARMA}(1,1)$} \\
\hline & $3 m$ & 0.0341 & $0.0299^{*}$ & 0.0258 & $0.0232^{*}$ & 19.7553 & $16.7393^{*}$ & 0.1139 & $0.0899^{*}$ \\
\hline & $6 m$ & 0.0422 & $0.0395^{\star}$ & 0.0319 & $0.0299^{*}$ & 24.3345 & $23.3982^{*}$ & 0.1436 & $0.1327^{*}$ \\
\hline & $9 \mathrm{~m}$ & 0.0459 & $0.0443^{*}$ & 0.0351 & $0.0344^{*}$ & 27.1057 & 27.2125 & 0.1584 & $0.1505^{*}$ \\
\hline & $12 \mathrm{~m}$ & 0.0491 & $0.0433^{*}$ & 0.0381 & 0.1583 & 29.5235 & 30.4585 & 0.1727 & $0.1666^{*}$ \\
\hline \multicolumn{10}{|l|}{ RW } \\
\hline & $3 m$ & 0.0341 & $0.0316^{*}$ & 0.0258 & 0.0316 & 19.7553 & $18.7100^{*}$ & 0.1139 & $0.1051^{*}$ \\
\hline & $6 m$ & 0.0422 & $0.0395^{\star}$ & 0.0319 & $0.0296^{*}$ & 24.3345 & $22.9353^{*}$ & 0.1436 & $0.1333^{*}$ \\
\hline & $9 \mathrm{~m}$ & 0.0459 & $0.0443^{*}$ & 0.0351 & $0.0341^{*}$ & 27.1057 & $26.6482^{*}$ & 0.1584 & $0.1515^{\star}$ \\
\hline & $12 \mathrm{~m}$ & 0.0491 & $0.0486^{*}$ & 0.0381 & $0.0380^{*}$ & 29.5235 & 29.6799 & 0.1727 & $0.1686^{*}$ \\
\hline
\end{tabular}

Australia and New Zealand are commodity-export dependent countries. They also share some distinctive economic structures and policies comparing to other countries. In this regard, considerations should not be solely given to commodity export components, but various other factors as well. Results in our study confirmed that there is a strong and robust relationship between the exchange rate and commodity prices in Australia and New Zealand.

Secondly, evidences have indicated that the cross exchange rate between NZD and AUD can be better measured and forecasted than the direct quoted (against USD) exchange rate pairs. As illustrated in this paper, when including commodity prices as independent variables in our model, the NZD/AUD cross rate model not only outperforms other two models in almost every aspect, but also offers a remarkable forecasting ability. The commodity-price-augmented exchange model (NZD/AUD cross rate model) developed in this paper consistent- 
ly outperforms a random walk at short horizons according to four evaluating methods. However, there are some evidences suggest that, in out-of-sample forecasts, the superiority of such a model does slightly deteriorate as the forecasting horizon increases.

The attributes behind our empirical results are likely to be the "Enhanced Commodity Currencies Phenomenon", represented by the fact that both underlying currencies (NZD and AUD) are commodity currencies, and they are both subject to the "Commodity Currencies Phenomenon" discovered in recent literatures. In addition, there is a unique underlying economic relationship between these two OECD nations: close geographically, free from trade restrictions, high co-movement in financial markets, and being contributing to our findings.

Results in this paper have provided further understanding of exchange rate dynamics to commodity prices. In addition, the superior and potential exploitable forecast ability of commodity-price-augmented exchange rate forecasting model may provide important information for nations that heavily rely on primary commodity production, and wish to develop the capital market liberalization by moving towards floating exchange rate regimes. The model developed in this paper can also benefit portfolio managers in better modeling NZD/AUD cross rates, hence, making better strategic decisions on currency trading and portfolio rebalancing.

\section{References}

[1] Meese, R.A. and Rogoff, K. (1983) Empirical Exchange Rate Models of the Seventies: Do They Fit out of Sample? Journal of International Economics, 14, 3-24.

[2] Meese, R.A. and Rogoff, K. (1983) The Out-of-Sample Failure of Empirical Exchange Rate Models. In: Frenkel, J.A., Ed., Exchange Rates and International Macroeconomics, University of Chicago Press, Chicago, 67-112.

[3] Mussa, M. (1979) Empirical Regularities in the Behavior of Exchange Rates and Theories of the Foreign Exchange Market. In: Brunner, K. and Meltzer, A.H., Eds., Policies for Employment, Prices, and Exchange Rates, North-Holland Pub. Co., New York, 9-57.

[4] Calvo, G. and Rodriguez, C. (1977) A Model of Exchange Rate Determination under Currency Substitution and Rational Expectations. Journal of Political Economy, 85, 617-626. https://doi.org/10.1086/260586

[5] Stockman, A.C. (1980) A Theory of Exchange Rate Determination. Journal of Political Economy, 88, 673-698. https://doi.org/10.1086/260897

[6] Lucas, R. (1982) Interest Rates and Currency Prices in a Two-Country World. Journal of Monetary Economics, 10, 335-359.

[7] Cashin, P., Cespedes, L. and Sahay, R. (2004) Commodity Currencies and the Real Exchange Rate. Journal of Development Economics, 75, 239-268.

[8] Chen, Y. and Rogoff, K. (2003) Commodity Currencies. Journal of International Economics, 60, 133-160.

[9] Luo, C. and Plantier, C. (2003) The Persistence of NZ Dollar Misalignments Relative to Purchasing Power Parity (Research Paper Series, Paper 09-2003). Auckland University of Technology. 
[10] Chen, Y. (2004) Exchange Rates and Fundamentals: Evidence from Commodity Economies. University of Washington, Working Paper.

[11] Chen, Y. and Rogoff, K. (2006) Are the Commodity Currencies an Exception to the Rule? University of Washington, Working Paper.

[12] Amano, R. and Norden, S. (1995) A Forecasting Equation for the Canada-U.S. Dollar Exchange Rate. The Exchange Rate and the Economy (207-65), Bank of Canada, Ottawa.

[13] Gruen, D.R. and Wilkinson, J. (1994) Australia's Real Exchange Rate-Is It Explained by the Terms of Trade or by Real Interest Differentials? Economic Record, 70, 204-219. https://doi.org/10.1111/j.1475-4932.1994.tb01839.x

[14] De Gregorio, J. and Wolf, H.C. (1994) Terms of Trade, Productivity, and the Real Exchange Rate (Working Papers 94-19). New York University.

[15] Chinn, M. and Johnston, L. (1996) Real Exchange Rate Levels, Productivity and Demand Shocks: Evidence from a Panel of 14 Countries. Working Paper 5709, NBER.

[16] Montiel, P.J. (1997) Exchange Rate Policy and Macroeconomic Management in ASEAN Countries. In: Hinklin, J., Robinson, D. and Singh, A., Eds., Macroeconomic Issues Facing ASEAN Countries, International Monetary Fund, Washington DC, 253-298.

[17] Chen, Y., Rogoff, K. and Rossi, B. (2008) Can Exchange Rates Forecast Commodity Prices? Working Paper 13901, NBER.

[18] Munroe, A. (2004) What Drives the New Zealand Dollar. Reserve Bank of New Zealand Bulletin, 67 (June). 


\section{Appendix A}

\section{CBA NZ Commodity Price Index (base at 01/01/1986 = 100)}

The Commonwealth Bank New Zealand Commodity Price Index is based on 18 different commodities that make up over $60 \%$ of New Zealand's total merchandise exports. The index includes: the major forestry products (logs, pulp, paper); dairy products (e.g. whole \& skim milk powder, butter, cheese, and casein); other livestock products (e.g. wool, lamb, \& beef, leather and skins); assorted commodities such as aluminium, fruit, fish, and crude petroleum products. The commodity weights are determined by the importance of each commodity in New Zealand's trade, i.e. Dairy 35\%, Forestry 20\%, Livestock 30\%, Fishery $8 \%$, Aluminum 7\%. For example, in 2010 the CBA NZ Commodity Price Index weights are based on contributions to merchandise exports in the previous year (2009). The weights for 2010 are: Wool 0.033; Beef 0.093; Lamb 0.150; Venison 0.013; Skins 0.019; Dairy 0.383; Apples 0.021; Kiwifruit 0.053; Logs 0.049; Sawn Timber 0.045; Wood Pulp 0.030; Seafood 0.065; Aluminium 0.046.

\section{RBA Commodity Index SDR (Index of Commodity Prices)}

The ICP is a Laspeyres index, which means that the index is a weighted average of recent changes in commodity prices. While the initial weight given to each commodity reflects its relative importance in total commodity export earnings in the base period, at any point in time thereafter the effective weight of each commodity in the index reflects the impact of subsequent changes in its price. However, since export values change as a result of movements in quantities exported as well as changes in prices, it is necessary to update periodically the base-period weights to reflect changes in export volumes. In addition, since the importance of individual commodities in Australia's export values changes over time-with the weight of some commodities becoming very small while others rise in importance-it is necessary to periodically review the commodities that are included in the index. RBA staffs have recently completed such a review, with updating conducted in 2003. As a result, the following changes have been made:

- the ICP will be re-based from 2001/02 to 2008/09;

- crude oil will be reintroduced to the index and the whole history of the ICP back-cast accordingly; and

- milk powder will be added and rice will be excluded from the index, back-cast to July 2008.

The updated index will include the prices of 20 of Australia's key commodity exports, which currently account for around 85 per cent of primary commodity export earnings. The re-basing to 2008/09 and addition of crude oil have a noticeable effect on the weights of each sub-index and individual commodity; adding milk powder and excluding rice have only small effects on the ICP.

The following table shows the weights of each component in the RBA Commodity Index SDR.

USA S\&P GSCI Non-Energy Spot-Price Index

The S\&P GSCI is world-production weighted; the quantity of each commodity 
Table A1. Commodity Price Weights (in \%).

\begin{tabular}{|c|c|c|c|c|}
\hline & \multicolumn{2}{|c|}{ Current index weights } & \multicolumn{2}{|c|}{ Updated index weights } \\
\hline & Initial 2001/02 & Effective 2008/09 & Initial 2008/09 & Effective Sep 2009 \\
\hline Rural commodities & 29.1 & 17.1 & 10.3 & 12.5 \\
\hline Beef and veal & 7.9 & 4.1 & 3.2 & 4.1 \\
\hline Wheat & 8.3 & 5.3 & 3.2 & 2.9 \\
\hline Wool & 4.1 & 2.0 & 1.1 & 1.6 \\
\hline Milk powder & - & - & 0.8 & 1.0 \\
\hline Sugar & 2.5 & 1.6 & 0.7 & 1.5 \\
\hline Barley & 1.9 & 1.3 & 0.6 & 0.6 \\
\hline Canola & 1.0 & 0.7 & 0.4 & 0.5 \\
\hline Cotton & 2.8 & 1.5 & 0.3 & 0.4 \\
\hline Rice & 0.5 & 0.7 & - & - \\
\hline Base metals & 15.7 & 10.8 & 6.8 & 9.6 \\
\hline Aluminium & 8.1 & 3.9 & 3.4 & 4.1 \\
\hline Copper & 2.8 & 3.1 & 1.8 & 2.8 \\
\hline Lead & 0.7 & 0.8 & 0.6 & 1.2 \\
\hline Zinc & 1.5 & 0.9 & 0.6 & 1.0 \\
\hline Nickel & 2.6 & 2.0 & 0.4 & 0.6 \\
\hline Other resources & 55.3 & 72.1 & 82.9 & 77.9 \\
\hline Metallurgical coal & 14.7 & 28.1 & 23.3 & 15.9 \\
\hline Iron ore & 9.3 & 15.1 & 21.8 & 20.8 \\
\hline Thermal coal & 9.7 & 10.7 & 11.4 & 9.8 \\
\hline Gold & 9.4 & 10.0 & 10.8 & 15.1 \\
\hline LNG & 4.8 & 3.9 & 6.5 & 5.1 \\
\hline Crude oil & - & - & 5.3 & 7.3 \\
\hline Alumina & 7.4 & 4.3 & 3.8 & 3.8 \\
\hline
\end{tabular}

in the index is determined by the average quantity of production in the last five years of available data. Such weighting provides the S\&P GSCI with significant advantages, both as an economic indicator and as a measure of investment performance. Below is a table from Goldman Sachs shown the most recent S\&P GSCI index components and weight. For more detail about this index, readers can refer to following web address:

http://www2.goldmansachs.com/services/securities/products/sp-gsci-commodity -index/tables.html

\section{S \& P GSCI ${ }^{\text {nx }}$ Components and Weights}

Currently, 24 commodities meet the eligibility requirement for the S\&P $\mathrm{GSCI}^{\mathrm{ma}}$. A list of these components and their dollar weights in the S\&P GSCI ${ }^{\mathrm{max}}$ organized by subsector, is presented in Table A2 below. 
Table A2. AS\&P GSCI ${ }^{\mathrm{TM}}$ Components and Dollar Weights (\%) (October 6, 2010).

\begin{tabular}{|c|c|c|c|c|c|c|c|c|c|}
\hline Energy & 68.3 & Industrial & & Precious & & Agriculture & 15.18 & Livestock & 4.39 \\
\hline Crude Oil & 35.65 & Metals & 0.37 & Metals & 0.00 & Wheat & 3.53 & Live Cattle & 2.57 \\
\hline Brent Crude Oil & 14.58 & Aluminium & 2.6 & Gold & 3.13 & Red Wheat & 0.73 & Cattle & 0.42 \\
\hline RBOB Gas & 4.3 & Copper & 3.88 & Silver & 0.42 & Corn & 3.8 & Lean Hogs & 1.4 \\
\hline Heating Oil & 4.66 & Lead & 0.49 & & & Soybeans & 2.29 & & \\
\hline Gas Oil & 5.92 & $\mathrm{Ni}$ & & & & Cotton & 1.4 & & \\
\hline \multirow[t]{3}{*}{ Natural Gas } & 3.21 & Kel & 0.92 & & & Sugar & 2.29 & & \\
\hline & & Zinc & 0.69 & & & Coffee & 0.85 & & \\
\hline & & & & & & Cocoa & 0.31 & & \\
\hline
\end{tabular}

\section{Appendix B}

\section{An out-of-sample forecasting example: 3-month-ahead forecast}

First, as we mentioned in the in-sample forecasting section, our sample period of in-sample forecasting is the full data set from January 1986 to January 2010. However, due to the consideration of the exchange rate regime shift, we define out-of-sample forecasting period as from February 1990/March 1993 to January 2010. We set May 2002 as time " $\mathrm{t}$ ", we assume it is the last month of the "in-sample" period and it is 3-month before the "out-of-sample" forecasting period. Next, we derive NZD/AUD long term fair value by adopting either one of the four methods we mentioned in the paper. Here, for simplicity, we assume FVs are all known and same as the FV values estimated in the in-sample forecasting. Having the FVs, we can then generate a series of values termed "departures from NZD/AUD Fair Value" by subtract the actual NZD/AUD exchange rates from corresponding FVs. This will give us 148 observations (from February 1990 to May 2002). We then perform the following regression for the departure from NZD/AUD cross rate fair value on independent variables:

$$
\begin{aligned}
\text { Error }_{t+k}= & \alpha+\beta_{1}\left(\text { Error }_{t+k-1}\right)+\beta_{2} \Delta\left(\text { Error }_{t+k-1}\right)+\beta_{3} \Delta\left(\text { Ral.GDP }_{t+k-4}^{N Z \& A U}\right) \\
& +\beta_{4}\left(\text { NZ.ComPr }_{t+k-1}\right)+\beta_{5}\left(\left(\text { AU }_{\text {ComPr }} r_{t+k-1}\right)+\varepsilon_{t+k}\right.
\end{aligned}
$$

We then use corresponding parameters from above regression model to forecast the departure value of 3 month-ahead. And the forecasted departure is added to the corresponding FV value to derive the " 3 month-ahead-forecasted exchange rate". Hence, the forecasting error at time $t+3$ is: $F E_{t+3}=S_{t+3}-\widehat{S_{t+3}}$, where $S_{t+3}$ represents the 3-month-ahead forecast. To do the out-of-sample forecast of further 3 month-ahead NZD/AUD exchange rate from time " $t+3$ ", the same process is repeated, but with 3 more set of observations added into the initial 148 observations as they become available at time " $t+3$ ".

Other out-of-sample forecasting in different time horizons and/or with different sample period are conducted in similar fashion with the same underlying rationales. 
Table A3. OLS tests of possible structure break.

\begin{tabular}{|c|c|c|c|c|c|c|c|c|c|c|c|c|c|c|c|c|c|c|}
\hline & \multicolumn{6}{|c|}{ NZD/AUD } & \multicolumn{5}{|c|}{ NZD/USD } & \multicolumn{7}{|c|}{ AUD/USD } \\
\hline & \multicolumn{2}{|l|}{ OLS Test } & \multicolumn{3}{|c|}{ OLS + Break dummy } & \multicolumn{3}{|c|}{ OLS Test } & \multicolumn{3}{|c|}{ OLS + Break dummy } & \multicolumn{3}{|c|}{ OLS Test } & \multicolumn{4}{|c|}{ OLS + Break dummy } \\
\hline Momentum & 0.952 & $* * *$ & 0.962 & $* * *$ & 0.965 & $* * *$ & 0.982 & $* * *$ & 0.996 & $* * *$ & 0.976 & $* * *$ & 0.987 & $* * *$ & 0.983 & $* * *$ & 0.957 & $* * *$ \\
\hline \multirow{3}{*}{ Mean Reversion } & $(56.805)$ & & $(57.909)$ & & $(44.763)$ & & $(73.795)$ & & $(66.960)$ & & $(34.829)$ & & 70.46345 & & 65.06186 & & 35.41659 & \\
\hline & -0.130 & $* *$ & -0.127 & * & -0.204 & $* *$ & -0.058 & & -0.177 & $* *$ & -0.113 & & -0.075 & & -0.190 & $* *$ & -0.140 & \\
\hline & $(-2.077)$ & & $(-1.848)$ & & $(-2.364)$ & & $(-0.794)$ & & $(-2.043)$ & & $(-0.895)$ & & -0.95738 & & -2.16437 & & -1.22082 & \\
\hline \multirow[t]{2}{*}{ Ral.GDP.NZ\&AU } & 0.189 & $* *$ & 0.221 & $* *$ & 0.365 & $* * *$ & & & & & & & & & & & & \\
\hline & $(2.177)$ & & $(2.492)$ & & $(2.982)$ & & & & & & & & & & & & & \\
\hline Ral.GDP.AU\&NZ & & & & & & & & & & & & & $(1.955)$ & & $(1.544)$ & & $(1.615)$ & \\
\hline \multirow[t]{2}{*}{ Ral.GDP.NZ\&US } & & & & & & & 0.120 & & 0.161 & * & 0.188 & * & & & & & & \\
\hline & & & & & & & $(1.304)$ & & $(1.722)$ & & $(1.615)$ & & & & & & & \\
\hline \multirow[t]{2}{*}{ NZ Commodity Prices } & -0.210 & $* * *$ & -0.208 & $* * *$ & -0.118 & & -0.219 & $* * *$ & -0.289 & $* * *$ & -0.209 & $* *$ & & & & & & \\
\hline & $(-3.748)$ & & $(-3.312$ & & $(-1.381)$ & & $(-3.922)$ & & $(-4.516)$ & & $(-2.257)$ & & & & & & & \\
\hline \multirow[t]{2}{*}{ AU Commodity Prices } & 0.179824 & $* * *$ & -0.1846 & $* * *$ & 0.228426 & $* *$ & & & & & & & -0.33262 & $* * *$ & -0.29504 & $* * *$ & -0.23721 & $* *$ \\
\hline & $(3.526)$ & & $(2.782)$ & & $(2.341)$ & & & & & & & & $(-5.323)$ & & $(-3.879)$ & & $(-2.071)$ & \\
\hline \multirow[t]{2}{*}{ US Commodity Prices } & & & & & & & 0.003 & & 0.019 & & 0.004 & & 0.042 & & 0.089 & * & 0.086 & \\
\hline & & & & & & & $(-0.078)$ & & $(0.416)$ & & $(0.059)$ & & $(0.982)$ & & $(1.816)$ & & $(1.288)$ & \\
\hline Adj.R^2 & 0.928 & & 0.931 & & 0.929 & & 0.954 & & 0.956 & & 0.954 & & 0.948 & & 0.952 & & 0.949 & \\
\hline No. obs. & 268 & & 243 & & 170 & & 268 & & 243 & & 170 & & 268 & & 243 & & 170 & \\
\hline Sample period & $1986 \mathrm{~N}$ & $11-20$ & 10M1 & & & & & & & & & & & & & & & \\
\hline
\end{tabular}

This table reports the original OLS regression results as well as the OLS results after each breaking point is added into the regression models, where $\beta t=1$ if $\mathrm{t} \geq$ 1 Breakpoint and $\beta t=0$ otherwise. Breakpoints are selected as the starting of the year 2000 and end of the year 2007 to reflex two of the most recent major global financial crisis. Corresponding t-statistics are reported in parentheses. No.obs is the number of observations. ${ }^{*},{ }^{* *},{ }^{* *}$ indicate $10 \%, 5 \%, 1 \%$ significant level. 